\title{
Clinical and Histopathological Characteristics of Tumors Arising in Seborrheic Keratosis: A Study of I 365 Cases
}

\section{Qian Ye \\ Ke-Jun Chen \\ Meng Jia \\ Sheng Fang (D)}

Department of Dermatology, The First Affiliated Hospital of Chongqing Medical University, Chongqing, 400016, People's Republic of China
Correspondence: Sheng Fang Department of Dermatology, The First Affiliated Hospital of Chongqing Medical University, No. I Youyi Road, Yuzhong

District, Chongqing, 400016, People's Republic of China

Email fangshengderm@163.com
Objective: The aim of this study was to describe the clinical and histopathological characteristics of seborrheic keratosis (SK) with secondary tumor and identify associated factors. Methods: This study was a monocentric retrospective case-control study describing the factors associated with the development of tumors in SK. A total of 1365 patients with SK were admitted to our department between 2018 and 2021. All of the histopathological specimens and medical records of these patients were reviewed. We compared the data of 36 patients with tumors arising in SK with those of the remaining 1329 patients with only SK, which were designated the control group.

Results: The incidence of tumors arising in SK that were biopsied was $2.6 \%$. The tumor types included squamous cell carcinoma (SCC), basal cell carcinoma (BCC) and keratoacanthoma (KA). Compared with other patients with SK, elderly patients with immunosuppression, patients presenting surrounding erythema or ulceration, and those with SK in exposed areas had an increased possibility of developing a secondary tumor. Tumors arising within SK have the histopathological features of ulceration, cytologic atypia, mitosis, "malignant horn", trabecular cell cords, solar elastosis and severe inflammatory infiltration in the dermis.

Conclusion: SK can show malignant progression in a small fraction of SK cases that are biopsied. This study is the first report on the clinical and histopathological characteristics of tumors arising in SK and identifies relevant factors in an Asian population.

Keywords: seborrheic keratosis, tumor, clinical, histopathological

\section{Introduction}

Seborrheic keratosis (SK) is considered the most common benign cutaneous neoplasm lacking malignant potential. In general, the pathogenesis of SK is not clear. Studies have shown that it is characterized by genetic stability; however, multiple somatic alterations, such as activating mutations of FGFR3, PIK3CA, HRAS, KRAS, AKT1, and $E G F R$, exist in $89 \%$ of the lesions. ${ }^{1}$ Heidenreich et al $^{2}$ identified high allele frequencies of BRAF, CDKN2A and TERT and DHPH3 promoters, in addition to those previously identified, in SK. In addition, they found that a positive feedback loop between FGFR3 and FOXN1 stalls affected keratinocytes in a pro-differentiation manner and may prevent the malignant progression of SK. However, in recent years, the rate of tumorigenesis in SK has been reported to be higher than previously supposed; the incidence of tumors arising in SK was recently reported to be $7 \%$. $^{3}$ Some estimation bias may exist, as the biopsy rate depends on whether SKs are removed only if they are 
in some way atypical. Studies have reported that SK lesions in the presence of ulceration, bleeding and crusting may herald malignant progression. ${ }^{4}$ However, whether these factors are associated with tumorigenesis in SK has not yet been identified. Large-scale clinical and histopathological analyses of SK secondary tumors remain lacking. To shed light on this issue, we studied the clinical and histopathological characteristics of malignant tumors arising with or in SK (tumor-SK) and identified relevant factors.

\section{Materials and Methods}

\section{Materials}

Ethics approval was granted from the Ethics Committee of the First Affiliated Hospital of Chongqing Medical University. A retrospective review of patients seen at the First Affiliated Hospital of Chongqing Medical University, Chongqing, China, between January 2018 and March 2021 was conducted. All patients who underwent complete excisional biopsy and histopathological examination diagnosing SK were included in this study. All slides stained with hematoxylin-eosin (HE) were taken from the Dermatological Department of the First Affiliated Hospital of Chongqing Medical University. The clinical data were collected from inpatient or outpatient medical records, pathology application forms, etc. All cases had complete and detailed medical records. All of the patients had provided written informed consent to present their clinical data with no associated identifying information.

\section{Methods}

All patients were identified through a computer-generated search using the term "seborrheic keratosis" in the pathology results from the database of the First Affiliated Hospital of Chongqing Medical University $(n=1365)$. Thirty-six patients with SK and secondary tumor were enrolled in the study, and the remaining 1329 patients with only SK were designated the control group. We retrospectively analyzed the sex, age, clinical manifestations, histopathological characteristics and history of immunosuppression of the 36 patients with tumor-SK and the remaining 1329 patients with only SK. The histological changes in SK components were compared between the two groups. A clinical and pathological review of the lesions was performed independently by 3 dermatologists including corresponding author.

\section{Statistical Analysis}

Descriptive analyses were conducted to evaluate the clinical and histological data, including sex, age and location of SK, as well as the characteristics of secondary tumors associated with SK. Age is presented as the mean (range) age and was compared using Student's $t$-test. Categorical variables were compared using the $x^{2}$-test and Fisher's exact test. A P value less than 0.05 was considered statistically significant. Statistical analysis was performed using the statistical software SPSS for Windows version 23.0.

\section{Results}

\section{General Data of Patients with SK}

A total of 1365 patients with SK were identified. The general data are presented in Table 1. Among all the patients with SK, men accounted for $49.1 \%$ and women accounted for $50.9 \%$, with no significant bias with respect to sex. The age of the patients with SK ranged from 15 to 93 years, with a mean age of 57.5 years. SK was most commonly found in exposed areas, predominately the face $(35.9 \%)$, followed by the head and neck $(28.1 \%)$, the trunk (25.3\%), and the limbs (10.7\%).

\section{Clinical Presentation}

The clinical data regarding the tumor-SK and SK groups are presented in Table 2. Mean age in the tumor-SK group and SK group was 72.9 and 57.1 years, respectively $(\mathrm{P}<0.001)$. The statistical analysis revealed significant differences between the groups in the presence of clinically surrounding erythema $(86.1 \% ; \mathrm{P}<0.001)$ and ulceration $(41.7 \% ; \mathrm{P}<0.001)$. SK in an exposed area (face, neck and $\mathrm{V}$-area of the chest, outer forearms or the dorsum of hands) and immunosuppression were prevalent factors in the tumor-SK group, occurring in $94.4 \% \quad(\mathrm{P}=0.002)$ and

Table I Characteristics of Patients with SK $(n=1365)$

\begin{tabular}{|l|l|l|}
\hline \multicolumn{2}{|l|}{ Characteristics } & Percentage \\
\hline Gender & Female & $695(50.9 \%)$ \\
& Male & $670(49.1 \%)$ \\
\hline Age (y) & $\leq 30$ & $54(4.0 \%)$ \\
& $31-49$ & $348(25.5 \%)$ \\
& $\geq 50$ & $963(70.5 \%)$ \\
\hline \multirow{2}{*}{ Locations } & Scalp and neck & $384(28.1 \%)$ \\
& Face & $490(35.9 \%)$ \\
& Limbs & $146(10.7 \%)$ \\
& Trunk & $345(25.3 \%)$ \\
\hline
\end{tabular}


$22.2 \%(\mathrm{P}<0.001)$ of patients, respectively. Patients who had undergone transplant, had HIV, or had a history of oral immunosuppressive drugs were classified as immunosuppression patients. Among the 36 patients in the tumorSK group, 6 patients presented bleeding (16.7\%), 2 patients presented with new neoplasms appearing on the skin lesions of SK (5.6\%), and 15 patients had symptoms such as pain and pruritus, accounting for $41.7 \%$, which demonstrated a nonsignificant difference $(\mathrm{P}>0.05)$.

\section{Histological Examination}

Among the 1365 patients with SK, 36 had secondary malignancies $(2.6 \%)$ (Table 3 ). Thirty patients had secondary squamous cell carcinoma (SCC), accounting for $83.3 \%$ of patients in the tumor-SK group, and comprised 26 patients with SCC in situ (Figure 1) and 4 patients with invasive SCC (Figure 2). There were 5 cases of secondary basal cell carcinoma (BCC) (Figure 3), comprising 3 cases of the nodular type, 1 case of the infiltrating type and 1 case of the superficial type; patients with secondary BCC accounted for $13.9 \%$ of the total malignant progression population in the tumor-SK group. One patient had tumors secondary to keratoacanthoma (KA) (Figure 4), accounting for $2.8 \%$ of patients in the tumor-SK group. In KA, the tumor architecture lacks the classical lipping of the edges
Table 3 Histological Features of 36 Patients with Tumor-SK

\begin{tabular}{|l|l|l|}
\hline \multicolumn{2}{|l|}{ Tumor-SK } & N (\%) \\
\hline SCC & SCC-in-situ & $26(72.2)$ \\
& Invasive-SCC & $4($ II.I) \\
\hline BCC & Nodular type & $3(8.3)$ \\
& Infiltrating type & I (2.8) \\
& Superficial type & I (2.8) \\
\hline KA & & I (2.8) \\
\hline
\end{tabular}

Abbreviations: Tumor-SK, tumor arising with or in seborrheic keratosis; $\mathrm{BCC}$, basal cell carcinoma; SCC, squamous cell carcinoma; KA, keratoacanthoma.

of the lesion. Pseudoepitheliomatous hyperplasia and very early verrucous carcinoma are alternative diagnoses to consider. The most common tumors associated with SK were SCC, followed by BCC and KA.

The frequencies of histopathological variables in the tumor-SK and SK groups are presented in Table 4. Significant between-group differences were revealed for histological ulceration $(55.6 \% ; \mathrm{P}<0.001)$, cytologic atypia (100.0\%; $\mathrm{P}<0.001)$, mitosis $(55.6 \%$; $\mathrm{P}<0.001)$, "malignant horn" (41.7\%; $\mathrm{P}<0.001)$, trabecular cell cords $(38.9 \%$; $\mathrm{P}<0.001)$, solar elastosis $(77.8 \% ; \mathrm{P}<0.001)$, and severe inflammatory infiltration in the dermis $(91.7 \%$; $\mathrm{P}<0.001)$. Among the 36 patients in the tumor-SK group, acantholysis

Table 2 Clinical Characteristics of Patients with Tumor-SK and SK n (\%)

\begin{tabular}{|c|c|c|c|c|}
\hline \multicolumn{2}{|l|}{ Characteristics } & \multirow{2}{*}{$\begin{array}{l}\text { Tumor-SK }(\mathrm{n}=36) \\
72.9 \text { (Years) }\end{array}$} & \multirow{2}{*}{$\begin{array}{l}\text { SK }(n=1329) \\
57.1 \text { (Years) }\end{array}$} & \multirow{2}{*}{$\begin{array}{l}P \text { value } \\
P<0.001\end{array}$} \\
\hline Mean age & & & & \\
\hline Sex & $\begin{array}{l}\text { Male } \\
\text { Female }\end{array}$ & $\begin{array}{l}\text { II (30.6) } \\
25(69.4)\end{array}$ & $\begin{array}{l}659(49.6) \\
670(50.4)\end{array}$ & $P=0.167$ \\
\hline Surrounding erythema & $\begin{array}{l}\text { Yes } \\
\text { No }\end{array}$ & $\begin{array}{l}31(86.1) \\
5(13.9)\end{array}$ & $\begin{array}{l}196(14.7) \\
1133(85.3)\end{array}$ & $P<0.001$ \\
\hline Bleeding & $\begin{array}{l}\text { Yes } \\
\text { No }\end{array}$ & $\begin{array}{l}6(16.7) \\
30(83.3)\end{array}$ & $\begin{array}{l}95(7.1) \\
1234(92.9)\end{array}$ & $P=0.067$ \\
\hline Neoplasma & $\begin{array}{l}\text { Yes } \\
\text { No }\end{array}$ & $\begin{array}{l}2(5.6) \\
34(94.4)\end{array}$ & $\begin{array}{l}13(1.0) \\
1316(99.0)\end{array}$ & $P=0.057$ \\
\hline Ulceration & $\begin{array}{l}\text { Yes } \\
\text { No }\end{array}$ & $\begin{array}{l}15(4 I .7) \\
21(58.3)\end{array}$ & $\begin{array}{l}39(2.9) \\
1290(97.1)\end{array}$ & $P<0.00 I$ \\
\hline Symptoms (pain, pruritus) & $\begin{array}{l}\text { Yes } \\
\text { No }\end{array}$ & $\begin{array}{l}15(4 I .7) \\
21(58.3)\end{array}$ & $\begin{array}{l}452(33.3) \\
877(66.7)\end{array}$ & $P=0.339$ \\
\hline Exposed Area & $\begin{array}{l}\text { Yes } \\
\text { No }\end{array}$ & $\begin{array}{l}34(94.4) \\
2(5.6)\end{array}$ & $\begin{array}{l}942(70.9) \\
387(29.1)\end{array}$ & $P=0.002$ \\
\hline Immunosuppression & $\begin{array}{l}\text { Yes } \\
\text { No }\end{array}$ & $\begin{array}{l}8(22.2) \\
28(77.8)\end{array}$ & $\begin{array}{l}28(2.1) \\
130 \mid(97.9)\end{array}$ & $P<0.00 I$ \\
\hline
\end{tabular}



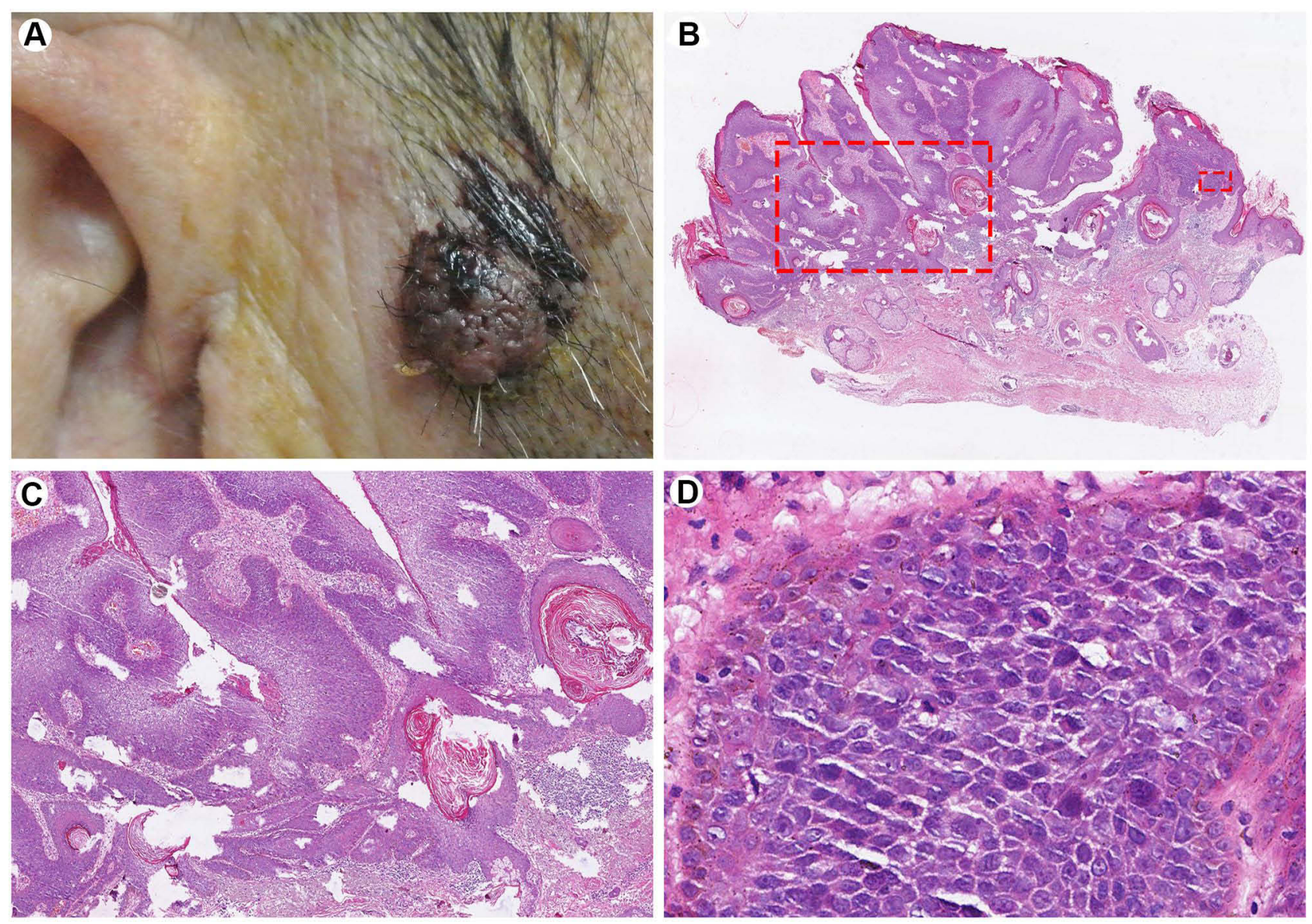

Figure I Clinical image and histological appearance of SCC in situ arising in seborrheic keratosis. (A) SCC in situ presented as a round-like nodule with a raised surface with crusting on face. (B and $\mathbf{C})$ The nest of squamous epithelial cells can be noticed (B, original magnification $\times / 0)$. Red-lined sections are presented in $(\mathbf{C}$ and $\mathbf{D})(\mathbf{C}$, original magnification $\times 40$; D, original magnification $\times 400$ ). (D) Mitosis and disorderly arrangement of cells are present. (B-D, Hematoxylin-eosin stain).

(38.9\%), spongiosis $(55.6 \%)$, squamous eddies $(50.0 \%)$, dyskeratocytes $(75.0 \%)$, necrosis $(8.3 \%)$, basal layer liquefaction $(72.2 \%)$, and pigment incontinence $(52.8 \%)$ were prevalent, all of which showed nonsignificant differences.

\section{Discussion}

SK is by far the most common cutaneous tumor encountered in clinical practice and primarily affects middle-aged and elderly people. The etiology of SK remains unclear; associations with human papillomavirus (HPV), melanocyte hyperplasia, genetic predisposition, and sun damage have been identified. ${ }^{5}$ Although SK appears to be genetically stable, multiple somatic alterations, such as FGFR3 and PIK3CA, HRAS, KRAS and EGFR mutations, exist in SK, which allow for the malignant transformation of seborrheic keratoses. ${ }^{1}$ According to recent studies, the incidence of tumorigenesis in SK varies between $1.4 \%$ and $7 \% .^{3,6}$ Our results revealed that among the 1365 patients diagnosed with SK who underwent biopsy, $36(2.6 \%)$ were found to have nonmelanoma skin cancer. In previous publications, the most common tumors reported to arise in SK were BCC followed by SCC. However, a variety of tumors may arise secondarily in SK, including adenocarcinoma, trichilemmal carcinoma, eccrine porocarcinoma and primary cutaneous ganglioneuroma. ${ }^{7-11}$ In the series of 36 patients with tumors arising in SK, there were 26 patients with SCC in situ, 4 patients with invasive SCC, 5 patients with BCC and 1 patient with KA. Although previous studies showed that BCC was the most common malignant neoplasm occurring within SK, our results are consistent with another study that showed SCC in situ to be the lesion most commonly associated with SK, ${ }^{12}$ although the number of invasive SCC cases was higher in that study than in the present study.

To the best of our knowledge, comparisons of clinical and histopathological characteristics between patients with malignant tumors arising in SK and a control group to identify associated risk factors have not been reported to date. Our study shows that the mean age in the tumor-SK 

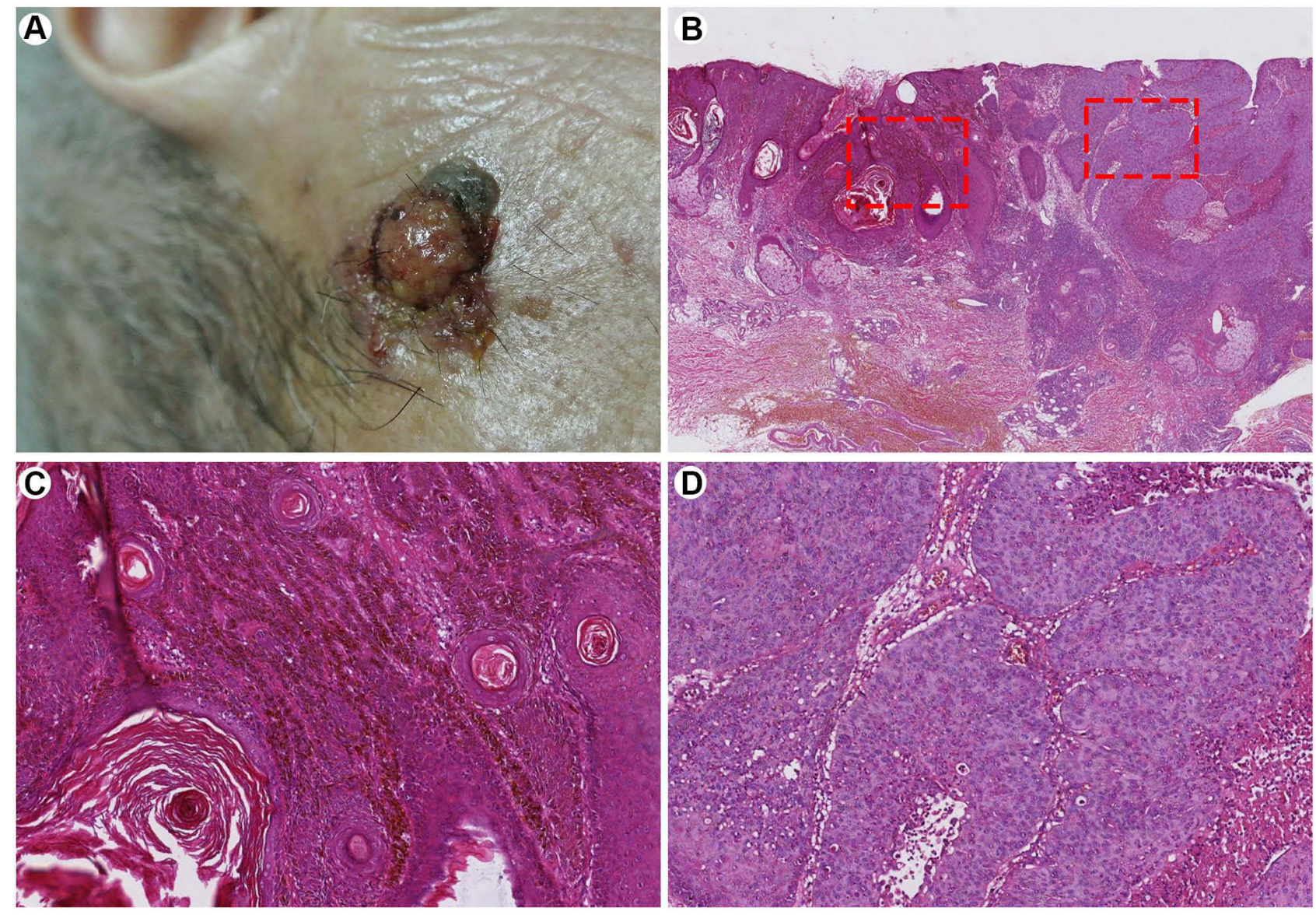

Figure 2 Clinical image and histological appearance of invasive SCC arising in seborrheic keratosis. (A) Invasive SCC presented as a neoplasm from the gray-black papule on face. (B and C) Pseudohorn cysts and trabecular cell cords can be observed (B, original magnification $\times 20)$. Red-lined sections are presented in (C and $\mathbf{D})$ (C), original magnification $\times 100$; D, original magnification $\times 100)$. (D) The nest of squamous epithelial cells, mitosis and disorderly arrangement of cells are present in the epidermis and dermis. (B-D, Hematoxylin-eosin stain).

group and the SK group was 72.9 and 57.1 years, respectively. This finding is consistent with the increasing incidence of tumorigenesis in SK as individuals age and strongly suggests that cumulative factors such as chronic photodamage may contribute to the development of tumors in SK. We also found that patients with immunosuppression have an increased possibility of developing secondary tumors in SK. Owing to the impairment of immune function, the frequency and presentation of skin disease, particularly skin tumors, change dramatically in patients with immunosuppression. Common diseases present in uncommon forms, and uncommon diseases present more commonly. Therefore, patients with immunosuppression have an increased risk of developing secondary tumors in SK. Under immunosuppression, the immune monitoring function of the body is weakened, and under the reductions in the functioning and number of local dendritic and CD4 cells, mutant cells can survive and proliferate. ${ }^{5}$ In addition, in elderly patients, immune function is weakened. This may be because $\mathrm{B}$ and $\mathrm{T}$ cells lose the ability to proliferate as aging progresses, leading to the loss of lymphocyte diversity. ${ }^{13}$

Although a previous study cannot claim to support sunlight as a possible factor in the malignant transformation of $\mathrm{SK},{ }^{14}$ our results confirmed a positive correlation between an exposed SK location and the incidence of tumor in SK. Our data demonstrated that tumorigenesis was more likely in cases where SK was in exposed areas, raising the possibility that sun exposure is important for the development of secondary tumors in SK; reducing sun exposure might help prevent such development. Heidenreich et al found that the mutational pattern in SK exhibited a typical ultraviolet (UV) signature, with the majority of alterations being $\mathrm{C}>\mathrm{T}$ and $\mathrm{CC}>\mathrm{TT}$ base changes at dipyrimidinic sites, which demonstrated a high proportion of UV-associated mutations. ${ }^{2}$ Seborrheic keratoses can be considered clinical markers of 



Figure 3 Clinical image and histological appearance of $B C C$ arising in seborrheic keratosis. (A) BCC presented as a black nodule with collapsing crust in the center on face. (B and $\mathbf{C})$ The nests of basophils cells can be noticed (B, original magnification $\times 20)$. Red-lined sections are presented in $(\mathbf{C}-\mathbf{F})(\mathbf{C}$, original magnification $\times 200$; $\mathbf{D}$, original magnification $\times 100$; E, original magnification $\times 100 ; \mathbf{F}$, original magnification $\times 200$ ). (D) The tumor cells are basaloid cells, with palisading of the cells. (E) Pseudohorn cysts can be observed. The basaloid cells show attachment to the epidermis. (F) Mucin deposition is present. (B-F, Hematoxylin-eosin stain).
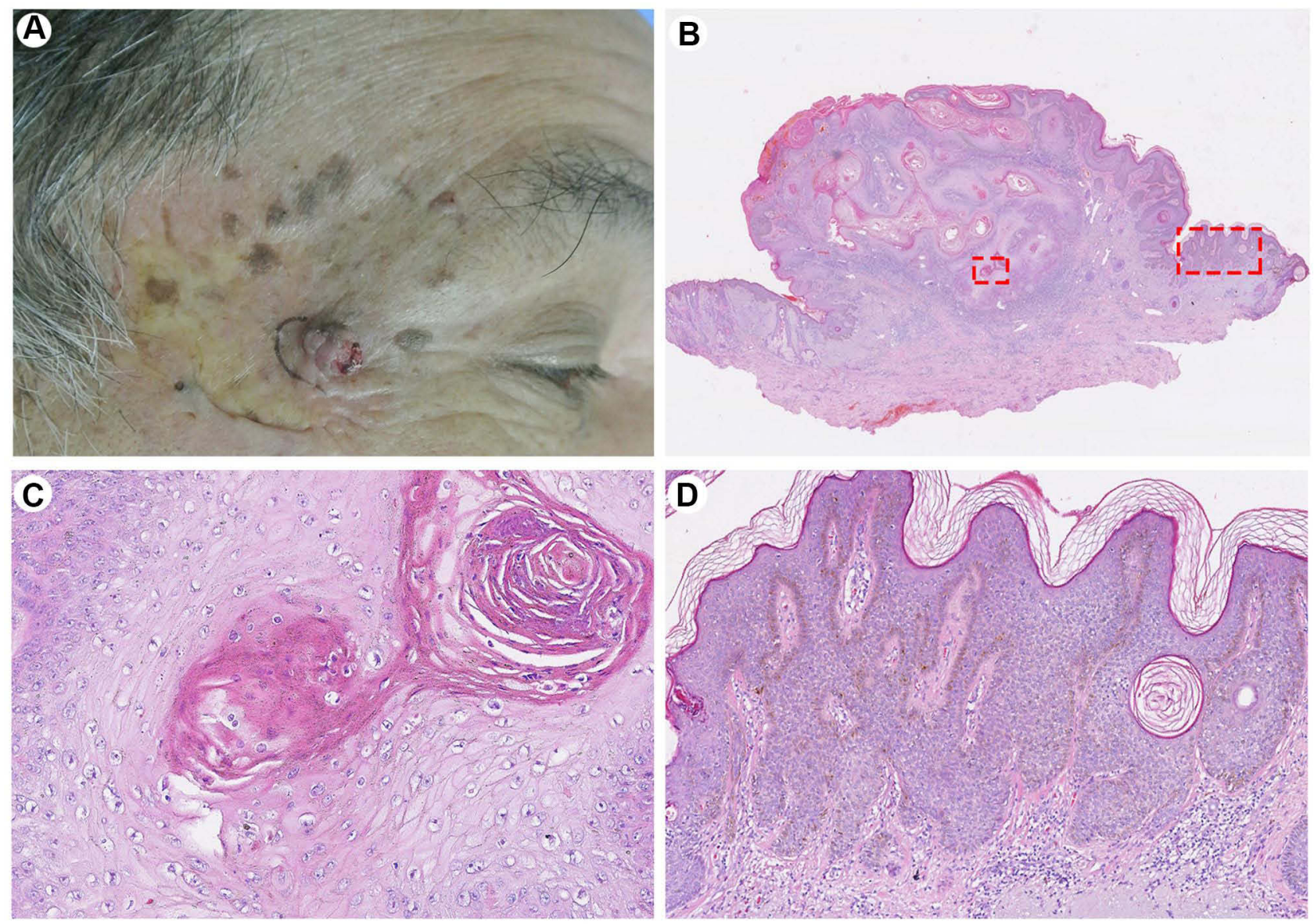

Figure 4 Clinical image and histological appearance of KA arising in seborrheic keratosis. (A) The gray-black papule with crusting on the surface of face. (B and C) Pseudohorn cysts, trabecular cell cords and solar elastosis can be observed (B, original magnification $\times 10)$. Red-lined sections are presented in (C and $\mathbf{D})(\mathbf{C}$, original magnification $\times 100$; D, original magnification $\times 200$ ). (D) Large, pale squamous cells with keratinization. (B-D, Hematoxylin-eosin stain). 
Table 4 Frequency of Histopathology Variables in Tumor-SK and SK n (\%)

\begin{tabular}{|l|l|l|l|}
\hline Pathological Feature & Tumor-SK (n=36) & SK (n=1329) & P value \\
\hline Malignant hyperkeratosis & $15(41.7)$ & $143(10.8)$ & $\mathrm{P}<0.00 \mathrm{I}$ \\
Ulceration & $20(55.6)$ & $15 I(11.4)$ & $\mathrm{P}<0.00 \mathrm{I}$ \\
Acanthosis & $14(38.9)$ & $462(34.8)$ & $\mathrm{P}=0.608$ \\
Spongiosis & $20(55.6)$ & $590(44.4)$ & $\mathrm{P}=0.184$ \\
Squamous eddies & $18(50.0)$ & $479(36.0)$ & $\mathrm{P}=0.086$ \\
Necrosis & $3(8.3)$ & $40(3.0)$ & $\mathrm{P}=0.07 \mathrm{I}$ \\
Dyskeratocyte & $27(75.0)$ & $936(70.4)$ & $\mathrm{P}=0.553$ \\
Cytologic atypia & $36(100.0)$ & $708(62.8)$ & $\mathrm{P}<0.00 \mathrm{I}$ \\
Mitosis & $20(55.6)$ & $297(53.3)$ & $\mathrm{P}<0.00 \mathrm{I}$ \\
Trabecular cell cords & $\mathrm{I}(38.9)$ & $\mathrm{I} 29(9.7)$ & $\mathrm{P}<0.00 \mathrm{I}$ \\
Basal layer vacuolization or liquefaction & $26(72.2)$ & $765(57.5)$ & $\mathrm{P}=0.079$ \\
Pigment incontinence & $19(52.8)$ & $594(44.7)$ & $\mathrm{P}=0.336$ \\
Solar elastosis & $28(77.8)$ & $477(35.9)$ & $\mathrm{P}<0.00 \mathrm{I}$ \\
Severe inflammatory infiltration & $33(91.7)$ & $289(21.7)$ & $\mathrm{P}<0.00 \mathrm{I}$ \\
\hline
\end{tabular}

Abbreviation: Tumor-SK, tumor arising with or in seborrheic keratosis.

sun damage. UV light is a known risk factor for malignant epithelial tumors, such as BCC and SCC, and future research may reveal its potential role in the development of secondary tumor in $\mathrm{SK} .{ }^{15}$

We also found that the clinical presentations of surrounding erythema and ulceration were likely relevant to tumorigenesis in SK and showed significant differences between the tumor-SK and SK groups. We found that surrounding erythema was usually pathologically associated with severe inflammatory infiltration in the dermis. Bleeding and symptom differences were not significantly different between the tumor-SK and SK groups, which suggested that these characteristics were the least important clinical signs of malignant progression. We think these changes are most likely subsequent to the presence of malignant cells manifested as clinical signs of secondary tumors rather than the cause of tumor formation. Clinicians and pathologists should be aware of the possibility of SCCs arising in SK and have increased suspicion when evaluating these types of lesions in patients who are immunosuppressed and present with surrounding erythema and ulceration on exposed sites.

The criteria for the diagnosis of tumor in SK include cytologic atypia and mitosis with features of SK such as hyperkeratosis, parakeratosis, papillomatosis, and pseudohorn cysts ${ }^{5}$ these criteria are consistent with the findings of our study. In our series, in addition to ulceration, cytologic atypia, mitosis and solar elastosis, we found that malignant horn and trabecular cell cords were significant features of SK with secondary tumor. The "malignant horn" is a compact, eosinophilic stratum corneum with hyperchromatic brick-like parakeratosis. ${ }^{16}$ In this study, most of the trabecular cell cords were found in cases where SK was in an exposed area, which may be associated with sunlight damage. ${ }^{17}$ The rapid growth of keratinocytes may lead to necrosis, ulceration and acantholysis. In addition, we observed that severe inflammatory infiltration in the dermis is associated with secondary tumor in SK. Inflammatory infiltration may cause damage to the basement membrane, leading to basal layer vacuolization or liquefaction and even pigment incontinence. Some epidermal and dermal changes were observed in SK, such as acantholysis, spongiosis, squamous eddies, dyskeratocytes, necrosis, basal layer vacuolization or liquefaction, and pigment incontinence, all of which showed nonsignificant differences between the tumor-SK and SK groups. Our study revealed significant between-group differences in histological findings, such as the presence of malignant horn, trabecular cell cords, solar elastosis, and severe inflammatory infiltration in the dermis, in addition to cytologic atypia and mitoses, which may be helpful information to consider when examining a specimen histologically.

$\mathrm{SK}$ is a common benign tumor that is rarely complicated by other tumors. Therefore, most cases of SK do not need treatment, only follow-up. However, when SK has atypical symptoms or the patient has aesthetic needs, treatment can be considered. ${ }^{18}$ In addition to surgical resection, cryotherapy, curettage or laser treatment can be considered. Seborrheic keratoses that have undergone recent clinical changes or appear inflamed or irritated should be considered for biopsy and histological examination. 
Controversy exists in the literature as to whether malignant epithelial tumors actually arise from SK or are simply concurrent with them. Some scholars believe that BCC may arise directly from the wall of pseudohorn cysts, ${ }^{19}$ and SCC arises from the eosinophilic spinous cell population around pseudohorn cysts, ${ }^{20}$ which indicates that secondary tumor may be associated with components in SK. However, a clear delimitation exists between the SK component and the associated carcinoma component, as we observed via microscopy in some cases in our series. Therefore, the possibility of collision tumor is present.

There are several limitations of this study. One limitation is its retrospective study design, which limited our ability to analyze data. In addition, restrictions have been imposed regarding the use of electronic medical records and search engines. A second limitation is that the incidence of SK with secondary tumor in this study seems higher than that previously supposed, which might be attributable to the fact that the object of our study was SK after biopsy and not all SK. This measurement does not reflect the frequency of tumors arising in all cases of SK, only that of tumors arising in SK that were biopsied. A third limitation is that although SK appears to be genetically stable, multiple somatic alterations, such as FGFR 3 and PIK3CA, HRAS, KRAS and EGFR mutations, ${ }^{1}$ exist that allow for the malignant transformation of seborrheic keratoses. To verify this possibility, molecular analyses of tumor cell subpopulations is needed to establish whether the clonal somatic mutations that characterize SK cells are also present in malignant tumor cells arising in SK lesions.

In conclusion, our study demonstrated that tumors arose in a small fraction of all SK cases that were biopsied. The most common secondary tumor of SK was SCC, followed by BCC and KA. The appearance of secondary tumor in SK occurs more often in immunosuppressed elderly patients with clinically surrounding erythema and ulceration in the exposed area than in other patients with SK. Histologically, malignant tumors arising in SK show ulceration, cell atypia, mitosis, "malignant horn", trabecular cell cords and severe inflammatory infiltration in the dermis, which may serve as signs of tumors arising in SK and deserve attention in clinical practice.

\section{Ethical Approval}

Ethical approval was given by the Medical Ethics Committee, the First Affiliated Hospital of Chongqing Medical University (Reference number: 2021-5). This study was conducted in accordance with the Declaration of Helsinki.

\section{Acknowledgments}

The patients in this manuscript have given written informed consent to publication of their case details.

\section{Author Contributions}

All authors made a significant contribution to the work reported, whether that is in the conception, study design, execution, acquisition of data, analysis and interpretation, or in all these areas; took part in drafting, revising or critically reviewing the article; gave final approval of the version to be published; have agreed on the journal to which the article has been submitted; and agree to be accountable for all aspects of the work.

\section{Funding}

There is no funding to report.

\section{Disclosure}

The authors declare no conflicts of interest related to this study.

\section{References}

1. Georgieva IA, Mauerer A, Groesser L, et al. Low incidence of oncogenic EGFR, HRAS, and KRAS mutations in seborrheic keratosis. Am J Dermatopathol. 2014;36(8):635-642. doi:10.1097/ DAD.0b013e31828c0542

2. Heidenreich B, Denisova E, Rachakonda S, et al. Genetic alterations in seborrheic keratoses. Oncotarget. 2017;8(22):36639-36649. doi:10.18632/oncotarget.16698

3. Lim C. Seborrhoeic keratoses with associated lesions: a retrospective analysis of 85 lesions. Australas J Dermatol. 2006;47(2):109-113. doi:10.1111/j.1440-0960.2006.00258.x

4. Anderson PJ, Zuk JA, Rao GS, Berry RB. Squamous cell carcinoma arising within seborrheic keratosis. Plast Reconstr Surg. 1998;102 (2):453-458. doi:10.1097/00006534-199808000-00027

5. Conic RZ, Napekoski K, Schuetz H, Piliang M, Bergfeld W, Atanaskova Mesinkovska N. The role of immunosuppression in squamous cell carcinomas arising in seborrheic keratosis. J Am Acad Dermatol. 2017;76(6):1146-1150. doi:10.1016/j.jaad.2016.12.002

6. Sloan JB, Jaworsky C. Clinical misdiagnosis of squamous cell carcinoma in situ as seborrheic keratosis. A prospective study. J Dermatol Surg Oncol. 1993;19(5):413-416. doi:10.1111/j.1524-4725.1993.tb00367.x

7. Cascajo CD, Reichel M, Sánchez JL. Malignant neoplasms associated with seborrheic keratoses. An analysis of 54 cases. Am J Dermatopathol. 1996;18(3):278-282. doi:10.1097/00000372199606000-00007

8. Smith KJ, Skelton HG 3rd, Lupton GP, Palomino NJ. Adenocarcinoma arising in a seborrheic keratosis. Arch Dermatol. 1991;127(11):17381739. doi:10.1001/archderm.1991.01680100142033

9. Gupta D, Singh N, Goyal A, PCh T, Thappa DM. Squamous cell carcinoma in-situ and basal cell carcinoma arising from seborrheic keratosis in the same patient. Indian J Dermatol. 2016;61(1):126. doi:10.4103/0019-5154.174178

10. Al-Daraji WI, Al-Dawoud A. Primary cutaneous ganglioneuroma arising within a seborrheic keratosis: a rare association. Clin Exp Dermatol. 2005;30(2):137-140. doi:10.1111/j.13652230.2004.01667.x 
11. Madan V, Cox NH, Gangopadhayay M. Porocarcinoma arising in a broad clonal seborrhoeic keratosis. Clin Exp Dermatol. 2008;33 (3):350-351. doi:10.1111/j.1365-2230.2007.02659.x

12. Vun Y, De'Ambrosis B, Spelman L, et al. Seborrhoeic keratosis and malignancy: collision tumour or malignant transformation? Australas $J$ Dermatol. 2006;47(2):106-108. doi:10.1111/j.1440-0960.2006. 00242.x

13. Cook JE, Beverley PC. Analysis of lymphocyte diversity in the elderly: heteroduplex analysis and alternative techniques. Exp Gerontol. 2001;36(3):583-589. doi:10.1016/S0531-5565(00)00260-6

14. Cimpean I, Theate I, Vanhooteghem O. Seborrheic keratosis evolution into squamous cell carcinoma: a truly modified sun-related tumor? A case report and review of the literature. Dermatol Rep. 2019;11(1):7999. doi:10.4081/dr.2019.7999

15. D'Orazio J, Jarrett S, Amaro-Ortiz A, Scott T. UV radiation and the skin. Int $J$ Mol Sci. 2013;14(6):12222-12248. doi:10.3390/ ijms140612222
16. Dirk M. Elston and Tammie Ferringer: Dermatopathology. 3rd ed. Elsevier Ltd; 2018.

17. Maize JC, Snider RL. Nonmelanoma skin cancers in association with seborrheic keratoses. Clinicopathologic correlations. Dermatol Surg. 1995;21(11):960-962. doi:10.1111/j.1524-4725.1995.tb00533.x

18. Greco MJ, Bhutta BS. Seborrheic keratosis. In: StatPearls. Treasure Island (FL): StatPearls Publishing; February 7, 2021.

19. Shibao K, Okiyama N, Tanaka R, Maruyama H, Fujisawa Y, Fujimoto M. Nodulocystic basal cell carcinoma arising directly from a seborrheic keratosis: a rare case report. Indian J Dermatol. 2016;61(4):443-445. doi:10.4103/0019-5154.185720

20. Stagner AM, Jakobiec FA, Iwamoto MA. Invasive squamous cell carcinoma with clear cell change of the eyelid arising in a seborrheic keratosis. JAMA Ophthalmol. 2015;133(12):1476-1477. doi:10.1001/ jamaophthalmol.2015.3439

\section{Publish your work in this journal}

Therapeutics and Clinical Risk Management is an international, peerreviewed journal of clinical therapeutics and risk management, focusing on concise rapid reporting of clinical studies in all therapeutic areas, outcomes, safety, and programs for the effective, safe, and sustained use of medicines. This journal is indexed on PubMed Central, CAS,
EMBase, Scopus and the Elsevier Bibliographic databases. The manuscript management system is completely online and includes a very quick and fair peer-review system, which is all easy to use. Visit http://www.dovepress.com/testimonials.php to read real quotes from published authors. 